\title{
Os Significados da Sexualidade para a Pessoa com Estoma Intestinal Definitivo
}

\author{
The Sexuality Meanings for People with Permanent Bowel Ostomy
}

\author{
${ }^{1}$ MARIA ANGELA BOCCARA DE PAULA $;{ }^{2}$ RENATA FERREIRA TAKAHASHI; ${ }^{3}$ PEDRO ROBERTO DE PAULA
}

\author{
${ }^{1}$ Professor Assistente Doutor do Departamento de Enfermagem da Universidade de Taubaté. Mestre e Doutor em \\ Enfermagem pela EEUSP ; ${ }^{2}$ Professor Livre-Docente do Departamento de Enfermagem em Saúde Coletiva da EEUSP; ${ }^{3}$ \\ Professor Assistente Doutor do Departamento de Medicina da Universidade de Taubaté. Mestre e Doutor pela \\ Universidade Federal Paulista -Escola Paulista de Medicina. Departamento de Enfermagem da Universidade de \\ Taubaté. Escola de Enfermagem da Universidade de São Paulo. Departamento de Medicina da Universidade de Taubaté.
}

\begin{abstract}
PAULA MAB; TAKAHASHI RF; PAULA PR. Os Significados da Sexualidade para a Pessoa com Estoma Intestinal Definitivo. Rev bras Coloproct, 2009;29(1): 077-082.

RESUMO: Estudo exploratório, descritivo, e qualitativo a luz do referencial da Representação Social (RS). Objetivo: identificar a RS da pessoa com estoma intestinal sobre a sexualidade. Métodos: Participaram 15 estomizados, oito (F) e sete (M), com idade média 57,9 anos, assistidos no Ambulatório Regional de Especialidades de Taubaté, período agosto-setembro/2005. Os dados foram obtidos por entrevistas, as quais foram transcritas e submetidas à análise de conteúdo, originando a Unidade Temática: Os significados da sexualidade, sub-temas: sexualidade necessidade física, emocional e de partilha, lembranças desagradáveis, não prática e negação da sexualidade. Considerações Finais: A qualidade dos relacionamentos apareceu como elemento central do significado atribuído à sexualidade, determinando sistemas de referência para a vivência da mesma no pós-estoma. Conhecer o significado da sexualidade para a pessoa estomizada é necessidade para complementar e implementar ações assistenciais que contribuam para melhorar qualidade de vida e assistência prestada.
\end{abstract}

Descritores: Colostomia, Sexualidade, Subjetividade, Representação Social.

\section{INTRODUÇÃO}

Estoma é uma palavra de origem grega, que significa boca ou abertura, utilizada para indicar a exteriorização de qualquer víscera oca através do corpo. É uma das mais antigas operações realizadas sobre o aparelho digestório ${ }^{(1)} \mathrm{O}$ estoma pode ser temporário ou definitivo e é uma das estratégias cirúrgicas, por vezes necessária, que contribui para cura ou sobrevida da pessoa que dele necessita.

O estoma intestinal pode ter diversas denominações, a depender do segmento exposto, por exemplo, colostomia e ileostomia ${ }^{(2)}$. As colostomias e ileostomias geralmente fazem parte das abordagens terapêuticas de traumas físicos e de diversas doenças intestinais e do ânus, tais como: câncer colorretal, doenças inflamatórias intestinais, doença diverticular do cólon, colite isquêmica, polipose familiar, megacólon, incontinência anal e infecções anoperineais graves ${ }^{(3)}$.

A confecção de um estoma intestinal gera mudanças no cotidiano e estilo de vida da pessoa e de seus familiares, caracteriza uma invasão da intimidade física e psicológica, com diferentes graus de intensidade e tipos de repercussões ${ }^{(4)}$.

Um estoma acarreta alteração física visível e significativa do corpo, podendo transformá-lo num corpo privado de sua integridade, dinamismo e autonomia, causando conflitos e desequilíbrios interiores, por ve- 
zes alterando relações com o mundo exterior, inclusive no que se refere à vivência de sua sexualidade, uma vez que o mesmo modifica a imagem corporal ${ }^{(5,6)}$.

Esta condição vivida pode levar ao isolamento psicológico e social, interferindo nos relacionamentos familiar, com amigos, no trabalho e sexual, quase sempre permeados por sentimentos negativos, como a ansiedade, o medo e as dúvidas ${ }^{(4,7,8)}$. A insatisfação com o corpo alterado e com a perda de controle da eliminação de gazes e fezes acarreta diminuição da auto-estima e sentimentos de auto-exclusão ${ }^{(5,6)}$. Estes quando identificados, valorizados e trabalhados, por profissionais especializados, podem ajudar a pessoa e parceiro na adaptação às novas condições, na busca de novas estratégias de enfrentamento inclusive para uma vida sexual ativa e prazerosa, auxiliando nos processos de adaptação e reabilitação.

A sexualidade ultrapassa a necessidade fisiológica e tem relação direta com a simbolização do desejo. Não se reduz aos genitais, refere-se à emoção que o sexo pode produzir, transcende definições físicas e se coloca como algo mais difuso que permeia todos os momentos da vida, possui significados complexos, multifacetados e que concentram grande carga de subjetividade ${ }^{(9,10)}$.

Por esses motivos o objetivo deste estudo foi identificar as representações sociais (RS) da pessoa sobre a sexualidade nesta nova condição - ser estomizado, uma vez que expressam sentidos e percepções que as pessoas possuem dessa realidade ${ }^{(11)}$.

\section{MÉTODOS}

Estudo exploratório, descritivo, qualitativo sob a luz do referencial teórico - metodológico das Representações Sociais (RS), que estuda fenômenos de um grupo específico e os processos imaginários de seus integrantes ${ }^{(11)}$, por meio de categorias que explicam, justificam e questionam as ações e os sentimentos dessa realidade $^{(12)}$.

Os dados foram coletados por meio de entrevistas individuais, realizadas no período de agosto e setembro de 2005, em Taubaté (SP). Participaram do estudo 15 pessoas estomizadas que obedeciam ao critério de inclusão quanto ao tempo de estoma (um ano ou mais) e foram orientadas sobre o objetivo da investigação. $\mathrm{O}$ sigilo quanto à identidade do entrevistado foi garantido e depois de realizados os esclarecimentos necessários, este assinava o termo de Consentimento
Livre e Esclarecido. O projeto do estudo foi aprovado pelo Comitê de Ética em Pesquisa da Universidade de Taubaté (protocolo n³26/05).

A entrevista era iniciada pela obtenção de dados de identificação e caracterização da pessoa e serviços de saúde em que fazia o acompanhamento ambulatorial. Em seguida apresentada à pergunta norteadora do estudo:

- Quando se fala sobre sexualidade o que vem a sua mente?

As entrevistas foram gravadas, posteriormente transcritas e os dados obtidos submetidos à análise de conteúdo, que consiste num conjunto de técnicas de análise das comunicações, para busca de significações explícitas ou ocultas, manifestas ou latentes ${ }^{(13)}$, e o conhecimento do que está por trás das palavras, outras realidades que não estão claramente expressas nas mensagens.

A fase de leitura exaustiva na procura de termo ou expressão que reunia em si o significado do discurso revelando a essência do depoimento, as expressões - chave são denominadas de pré-análise. Estas expressões-chave buscam resgatar a literalidade dos depoimentos até a escolha do enfoque a ser utilizado para a análise dos depoimentos, que originaram a primeira categorização.

A etapa seguinte foi à fase dos recortes dos depoimentos e a verificação da frequência com que apareciam dentro das categorias, sendo então enquadrados em subcategorias iniciais, para na próxima etapa serem definitivamente categorizados na Unidade Temática resultante: OS SIGNIFICADOS DA SEXUALIDADE e seus subtemas.

\section{RESULTADOS E DISCUSSÃO}

\section{Caracterizando a população estudada}

Dos $15(100 \%)$ estomizados intestinais entrevistados, oito $(53,3 \%)$ eram do sexo feminino e sete $(46,7 \%)$ do sexo masculino. Em relação à faixa etária, oito $(53,3 \%)$ estavam entre 50 e 69 anos, sendo quatro $(26,6 \%)$ mulheres e quatro $(26,6 \%)$ homens, cinco $(33,3 \%)$ com 70 anos ou mais, sendo três $(20 \%)$ mulheres e dois $(13,4 \%)$ homens e, dois $(13,4 \%)$ entre 30 e 49 anos, sendo uma mulher e um homem.

Do total de mulheres cinco $(62,5 \%)$ eram casadas, duas $(25 \%)$ viúvas e uma $(12,5 \%)$ divorciada. Do total de homens cinco $(71,4 \%)$ eram casados, um $(14,3 \%)$ viúvo e um $(14,3 \%)$ solteiro. Dentre os casa- 
dos, o tempo de casamento foi de mais de 20 anos em quatro deles, três estavam casados entre cinco e nove anos, dois entre 10 e 15 anos, um entre 16 a 20 anos.

No que se refere à escolaridade dos participantes, dois $(13,3 \%)$ eram analfabetos, sete $(46,8 \%)$ tinham ensino fundamental incompleto, um $(6,6 \%)$ ensino fundamental completo, quatro $(26,7 \%)$ ensino médio completo e um $(6,6 \%)$ o ensino superior incompleto.

Quanto ao tipo de estoma intestinal, 12 (80\%) das pessoas eram colostomizadas definitivas à esquerda, devido ao câncer intestinal; duas $(13,4 \%)$ ileostomizadas em função de doenças inflamatórias crônicas intestinais; e, uma $(6,6 \%)$ tinha transversostomia em alça.

Em relação às atividades laborativas, seis (40\%) eram aposentadas, três (20\%) do lar, três (20\%) comerciantes, um $(6,6 \%)$ desempregado, um $(6,6 \%)$ comerciário e um $(6,6 \%)$ trabalhava como babá.

Em relação ao tempo de estoma, quatro pessoas $(26,7 \%)$ conviviam com o estoma de dois a cinco anos, dois $(13,3 \%)$ de seis a 10 anos, quatro $(26,7 \%)$ de 11 a 15 anos, dois $(13,3 \%)$ de 16 a 20 anos e três (20\%) há 21 anos ou mais.

Todos os entrevistados estavam cadastrados no pólo de atendimento ao estomizado de Taubaté e eram acompanhados pela enfermeira estomaterapeuta do serviço.

\section{xualidade}

Unidade Temática - Os Significados da Se-

A sexualidade foi compreendida como necessidade física, emocional e de partilha em seus relacionamentos em $66 \%$ (10/15) das respostas obtidas, na qual a questão do carinho, do gostar, do amor e do compartilhar apareceu concomitantemente.

Prazer, compartilhar, é isso!!! A5

.... é carinho, convivência, diálogo .... A1

.... é companheirismo, vida conjugal, compartilhar momentos de prazer....é uma necessidade física e emocional A14

É estar junto, é isso... envolve o desejo e o prazer A15

Esses recortes mostraram que para a pessoa estomizada, a prática da sexualidade compreendeu a expressão de emoções relacionadas à afetividade (paixão, amor), sensações físicas, em resposta aos estímulos sensoriais, ou seja, não se limitou ao impulso e ao ato sexual, mas constituiu uma dimensão que ia além do prazer físico, envolvendo momentos que geravam satisfação, prazer e bem-estar físico e emocional, desfrutados com outra pessoa.

Uma experiência ou ação só tem sentido quando é portadora de uma carga emocional, uma vez que "as emoções representam um momento essencial na definição do sentido subjetivo dos processos e relações do sujeito" (14).

Os significados atribuídos à sexualidade reafirmaram que o vínculo com o parceiro podia ser fortalecido com o diálogo, que aliado ao respeito e ao carinho mútuo, compunham um caminho fundamental para a busca do equilíbrio conjugal, sexual e do prazer partilhado, propiciando um relacionamento íntimo prazeroso e, a satisfação de necessidades físicas e emocionais, mesmo com a presença do estoma no corpo, no cotidiano, na vida.

O câncer intestinal foi a principal causa do estoma no grupo estudado, independente do tempo de confecção. Mesmo com os inúmeros avanços das técnicas cirúrgicas e dos tratamentos quimioterápicos e radioterápicos, que permitem o controle e até a cura do câncer, o seu diagnóstico continua associado a uma imagem negativa. A palavra câncer traz consigo significados ancorados na incerteza, no medo e relacionados a pouco tempo de vida, dificuldade de cura, perda, finitude e morte.

Para a pessoa estomizada, o diagnóstico do câncer surgiu como o componente novo, estranho ao seu sistema de pensamento, que foi incorporado aos valores e as representações pré-existentes e posteriormente concretizado em palavras, imagens e comportamentos. Tais representações sobre o câncer contribuíram para ampliar a percepção das pessoas a respeito da fragilidade de sua vida, as fizeram repensar valores, prioridades e projetos de vida, uma vez que as RS não se reduziam a um ato de cognição individual, mas foram sempre intermediadas pela subjetividade, sofrendo influência das histórias pessoal e social do indivíduo.

No grupo estudado, $11(73,3 \%)$ dos entrevistados eram estomizados há cinco anos ou mais, período este correspondente ao tempo necessário para considerar a ocorrência da cura da doença (nos casos de câncer), pela inexistência de recidivas. Tal fato é relevante uma vez que o impacto do diagnóstico do câncer na representação da sexualidade não foi identificado nos discursos coletados, uma vez que estas pessoas 
entrevistadas pareciam haver superado as incertezas e medos decorrentes do diagnóstico.

Compartilhar do diagnóstico com o parceiro constituiu um passo importante para auxiliar no processo de reabilitação da pessoa estomizada, pois possibilitou a expressão das ansiedades e inseguranças, além da chance de solicitar e receber apoio emocional, amor, empatia, cuidados, ajudando no enfrentamento da situação e influenciando favoravelmente o seu estado de saúde. É importante que o parceiro seja envolvido no plano assistencial da pessoa estomizada desde a fase pré-operatória para o sucesso do seu processo de adaptação ao estoma.

O apoio da família e do parceiro é essencial para o desenvolvimento de atitudes positivas frente à nova situação, tornando mais fácil e rápido o processo de recuperação pós-operatória, adaptação e retorno às atividades da vida diária, inclusive quanto à vivência da sexualidade ${ }^{(15)}$.

O processo de aceitação e adaptação ao estoma é evolutivo e sequencial, durante o qual, a pessoa desenvolve mecanismos de defesa, em que há negação e repressão das emoções, resultando em atitudes confusas, de regressão e hostilidade, geralmente direcionadas as pessoas mais próximas e afetivamente importantes (16). Essas considerações corroboram com a percepção de que o apoio familiar/parceiro foi essencial neste processo, somados à qualidade das relações aí estabelecidas.

A inexistência do apoio familiar associada à ausência de envolvimento dos familiares no processo de adaptação resultou na adoção de comportamentos de isolamento, afastamento do convívio social, laboral e da expressão da sua sexualidade, que caracterizaram negação ou não aceitação da doença e do estoma.

A vivência de uma enfermidade ou situação crônica é impregnada de significados que transcendem os limites da doença (relações pessoais, afetivas, sociais) e, portanto precisam ser considerados na individualidade de cada pessoa, de cada mundo, no decorrer de sua existência ${ }^{(14)}$.

A percepção de cada fenômeno agregado ao viver da pessoa seja uma doença, a possibilidade de cura ou sobrevida (com estoma) pode por um lado ter o significado de rever valores, hábitos, reorganizar a vida e buscar alternativas para adaptação, por outro lado, pode-se lhe atribuir significados negativos e destrutivos, para os quais a pessoa não encontrava soluções e conduziam ao isolamento e imobilização.
Ah por causa desse problema, antes a gente não tinha nada e agora com esse problema..... A4

As representações atribuídas ao estoma e doença integravam a forma como cada pessoa percebia as situações vivenciadas, determinando sua maneira de reagir diante delas, uma vez que "... estamos imersos em nosso mundo dos sentidos, do qual provêm todos os nossos conhecimentos; não podemos falar de uma causalidade, já que as mesmas causas nem sempre levam aos mesmos efeitos" ${ }^{(14)}$, rompendo com a linearidade de causa e efeito, propondo um olhar mais amplo e complexo sobre o concreto e as relações sociais, que sofreram influências da esfera individual e social, do pensamento, atividade e sentimento.

Este subtema configurou uma percepção positiva e abrangente da sexualidade, no qual estavam presentes dimensões físicas, psíquicas e sociais, ancoradas em representações de vivências pessoais e no conhecimento empírico que são base da existência individual, tal como a vida da pessoa no contexto da família e do trabalho.

Cerca de $30 \%$ dos depoimentos fizeram referência à sexualidade relacionando-a com lembranças desagradáveis, a não prática do ato sexual ou negação da sexualidade.

\author{
Não traz boas lembranças, muito \\ machucada, muito ruim... A11 \\ ... não sou muito envolvida com isso, nem \\ penso nessas coisas... A10 \\ ... penso e fico triste... A4
}

Esses recortes mostraram que a sexualidade para estas pessoas era percebida de forma negativa, talvez por ter sido vivenciada até então, de maneira pouco ou não prazerosa, em relacionamentos com problemas, desgastados ou pouco explorados, resgatando significados e representações ancorados nas suas histórias de vida.

As relações afetivas e sexuais são estruturadas e reformuladas por um sistema de significados, influenciados pela cultura e, portanto, determinadas por padrões de gênero, sociais, econômicos e culturas regionais ${ }^{(17)}$.

As experiências individuais somadas à história pessoal e contexto sócio-cultural em que a pessoa estava inserida foram fatores determinantes da maneira 
como a mesma iria reagir frente a novas e inesperadas situações, como doença e necessidade de estoma intestinal definitivo, influenciando diferentes esferas do viver, inclusive na sexualidade.

A presença do estoma intestinal somada ao contexto e exigências sociais pode representar grande carga emocional para a pessoa, que por vezes, sem vislumbrar alternativas se escondia, se isolava e evitava até mesmo pensar sobre a sexualidade, negando-a ou colocando-a de lado como dimensão esquecida ou reprimida. Outro ponto a ser considerado foi a questão dos relacionamentos pessoais com problemas, nos quais a situação de adoecimento e o estoma favoreciam ou determinavam o afastamento ou a interrupção da vivência da sexualidade pelos parceiros, que não era retomada sob a alegação socialmente aceita de que uma pessoa "doente" não deve praticar sexo, podendo significar um grande alívio para alguns.

Depois que fui operada a gente nem dorme mais no mesmo quarto A10

Para outros, a comunicação precária devido aos prévios problemas de relacionamento acentuavam ainda mais o afastamento da vida sexual e a falta de diálogo contribuiu para manter ou agravar a situação.

Ah!!! Conversei, mas... não deu... a gente vive meio assim...Mais ou menos, não era muito legal não... O marido não dava muito carinho essas coisas, era muito ruim. E depois que eu fui operada ficou pior ainda. A10

Os extremos que apareceram nos recortes acima, sobre o significado da sexualidade para a pessoa com estoma intestinal, permitiram perceber que no grupo estudado havia dois pólos. O do grupo de pessoas estomizadas que atribuíram significados "positivos" para a sexualidade, composto pelos discursos que referiram ter uma vida sexual prazerosa e agradável antes do estoma e os do grupo que atribuíram significados "negativos" para a sexualidade, composto pelos discursos de pessoas que mesmo antes do estoma tinham a sexualidade como algo pouco prazeroso ou desagradável. Isto vem corroborar com a ideia de que a sexualidade é uma configuração de sentido socialmente produzida direta ou indiretamente por registros emocionais de experiências anteriores singulares e es- pecíficas ${ }^{(16)}$ que certamente foram determinantes para a trajetória da vida da pessoa.

Na prática profissional foi possível notar que esta realidade estava presente nas pessoas de um modo geral e não apenas nos estomizados, pois quando as relações eram balizadas pelo respeito, amor, amizade e diálogo, as circunstâncias difíceis como doenças e outros agravos, foram gradativamente trabalhadas pelos parceiros na busca conjunta de soluções adequadas para ambos. Entretanto, quando existia a presença de desajustamentos na relação, estas situações de adoecimento acabavam muitas vezes, por definir o fim da relação ou o afastamento definitivo da prática da sexualidade com aquele parceiro, interferindo diretamente nos significados atribuídos a esta.

As experiências pessoais e anteriores a confecção do estoma compuseram a ancoragem das RS da pessoa estomizada acerca da sexualidade, se mostraram como base de definição de caminhos para a sua vivência no período pós-estoma, uma vez que as RS estão enraizadas no passado, nas tradições e na linguagem ${ }^{(18)}$.

\section{CONSIDERAÇÕES FINAIS}

O significado da sexualidade, a importância a ela atribuída pelas pessoas estomizadas, assim como suas representações foram elementos essenciais na determinação das mediações estabelecidas em relação a este aspecto para a retomada de suas trajetórias de vida.

A qualidade dos relacionamentos apareceu como elemento central do significado atribuído à sexualidade. Pessoas com relacionamentos estáveis a percebiam de forma positiva, como necessidade física e emocional a ser partilhada, e aquelas em que os relacionamentos apresentavam problemas prévios à confecção do estoma atribuíram significados negativos, negando ou evitando-a.

$\mathrm{Na}$ assistência à pessoa estomizada, a sexualidade é aspecto pouco abordado pelos profissionais de saúde, existindo ainda muita dificuldade de abordagem e questionamento sobre a temática, tanto por parte dos profissionais como por parte dos estomizados, contribuindo para que estas representações e significados sejam pouco conhecidos e explorados e, assim ações específicas para o atendimento desse aspecto (sexualidade) sejam pouco contempladas nos planos assistênciais. 
A capacitação permanente dos profissionais que compõem a equipe de saúde e o conhecimento dos significados atribuídos à sexualidade pelo estomizado poderá contribuir significativamente para a inclusão da sexualidade no leque de orientações na rotina de atendimento da equipe que o assiste, contribuindo para melhorar a qualidade de vida da pessoa assistida e a assistência prestada.

\begin{abstract}
Exploratory, descriptive, qualitative study based in the Social Representation (SR) reference. The aim of this study was identify the SR about sexuality of person with definitive intestinal stoma. Fifteen people attended this research, eight (F) and seven (M), with average age - 57,9 years, registered and assisted in Taubate Specialties Ambulatory- period of 2005/August September. Data were collected through interviews that were transcribed and submitted to the content analysis, causing Unit Focus: The meanings of sexuality, sub-themes: sexuality physical, emotional and sharing need, unpleasant memories, inattention and not practice. The quality of relationships emerged as central element of the meaning attributed to sexuality by interviewees, determining reference systems for their post-stoma life. Knowing the meaning of sexuality to the person is a need to complement and implement assistance actions that help and improve the quality of life and care.
\end{abstract}

Key words: Colostomy, Sexuality, Subjectivity, Social Representation.

\section{REFERÊNCIAS}

1. Zampieri JC, Jatobá PP, Histórico. In: Crema E, Silva E. Estomas: uma abordagem interdisciplinar. Uberaba: Pinti; 1997. p. 13-8.

2. Martins Jr A, Rocha JJR. Tipos de estomas intestinais: In: Crema E, Silva E Estomas: uma abordagem interdisciplinar. 1ed. Uberaba: Ed Pinti,1997p.41-64.

3. Habr-Gama A, Araújo SEA. Estomas intestinais: aspectos conceituais e técnicos. In: Santos VLCG, Cesaretti IUR. Assistência em Estomaterapia: Cuidando do ostomizado. São Paulo, Atheneu, 2000; p. 39-54.

4. Souza RHS, Montovani MF, Lenard T. Significados do corpo: reflexão teórica.Cogitare Enferm. 2001;6(2):25-30.

5. Silva AL, Shimizu HE. A relevância da rede de apoio ao estomizado. Rev. Bras Enferm. 2007;60(3):307-11.

6. Cesaretti IUR, Leite MG. Bases para o cuidar em enfermagem. In: Santos VLCG, CesarettiI UR. Assistência em estomaterapia: cuidando do ostomizado. São Paulo: Atheneu; 2000. p. 19-37.

7. Pereira APS. Educação Sexual de grupos de adultos portadores de Estomas intestinais definitivos: processo da implantação e Implementação. [dissertação]. Ribeirão Preto (SP): Escola de Enfermagem de Ribeirão Preto- USP; 2006.

8. Cascais AFMV, Martini JG, Almeida PJS. O impacto da ostomia no processo de viver humano. Texto \& Contexto Enferm. 2007;16(1):163-7.

9. Chauí M. Repressão sexual: essa nossa (des)conhecida. $7^{\mathrm{a}}$ ed. São Paulo: Brasiliense; 1984.
10. Diamantino EMV et al. Aspectos básicos da sexualidade humana na parte clínica. Parte I. Femina. 1993;21(10):1016-29.

11. Bison RAP. Representações Sociais dos estudantes de Enfermagem sobre sexualidade, numa experiência de ensino. [Dissertação] Ribeirão Preto (SP): Escola de Enfermagem da USP;1998.

12. Minayo MCS.O desafio do conhecimento: pesquisa qualitativa em saúde.São Paulo: Hucitec/Abrasco; 1994.

13. Bardin L. Análise de conteúdo. Lisboa: Edições 70, 1995.

14. Rey FG. Sujeito e subjetividade. São Paulo: Pioneira Thompson Learning; 2003.

15. Silva AL, Shimizu HE. O significado da mudança no modo de vida da pessoa com estomia intestinal definitiva. Rev LatinoAmEnfermagem; 2006; 14(4): 483-90.

16. Neder CR. Considerações conceituais sobre o suporte psicológico ao paciente ostomizado. In: Santos VLCG, Cesaretti IUR. Assistência em estomaterapia: cuidando do ostomizado. São aulo:Atheneu;2000. p. 327-34.

17. Leal AF, Knauth DR. A relação sexual como uma técnica corporal: representações masculinas dos relacionamentos afetivosexuais. Cad Saúde Pública. 2006;22(7):1375-84.

18. Marcová I. Dialogicidade e representações Sociais: Adinâmica da mente.Petrópolis, RJ:Vozes, 2006.

Endereço para correspondência:

MARIA ANGELA BOCCARA DE PAULA

Av. Itália 1551 - R1 Rua 1 n 234 - Jd das Nações

Taubaté - São Paulo

Fone: (12) 3633-6904

Email: boccaradepaula@vivax.com.br 